\title{
Achievement of Total Quality Is Impossibility
}

\author{
Xiaohang Wu \& Yafei Wang \\ School of Economics and Management, Chongqing Normal University \\ Chongqing 400047, China
}

\begin{abstract}
In the manufacturing industry, product quality has become a key factor in determining a firm's success or failure in the global marketplace. Advanced, highly reliable manufacturing methods have made it possible to achieve very high standards of product quality. As a result, more and more firms are making product quality a keystone of their competitive strategy. However, the improvement of production quality is a long-term commitment to continuous improvement in every aspect of the production process. To achieve the total quality, it needs the total quality control and the total quality management. Whether the organisation can realize the total quality, it depends on the success of these two aspects.
\end{abstract}

Keywords: Quality, Total quality control, The total quality management, Impossibility

\section{Introduction}

Quality is the "totality of features and characteristics of a product or service that bear on its ability to satisfy stated or implied needs." (Naylor, 1999) and the total quality as holistic concept involving everything an organization does in the pursuit of quality which include the customer satisfaction, continuous improvement, the importance of internal customers and an all-embracing approach demanding the involvement of all. During this time, however, the meaning of quality has changed. The fact that the quality revolution commenced in manufacturing meant that the natural evolution of total quality began with a focus on producing quality products. This involved considering what the problems with the product were and then assessing how related processes could be improved (Fred Palumb, 1994). To achieve the total quality, we need use the total quality control and the total quality management. Whether we can realize the total quality, it depends on the success of these two aspects. This paper will focus on these two points to critically analyse the achievement of total quality is possible or impossible.

\section{Total quality control}

To achieve the total quality, the organisation should do the total quality control firstly. In most of the organisation, the most popular current forms of total quality control is by use of the Zero-defects programmes.

Crosby stressed the role of worker attitude as being critical to a quality effort. As such, he suggested workers be given quality targets of zero-defects. He defined quality as conformity to certain specifications set forth by management and not some vague concept of "goodness". These specifications are not arbitrary either; they must be set according to customer needs and wants. According to Crosby's theory, when the organisation achieves the target of zero-defects, the total quality is achieved at the same time (Sinclair, 2001).

Juran proposed a curve of the cost of quality, he though when the quality improves to a certain degree, even if increased and improved a large amount of resources, the results are not obvious (Francois, 2003). The so called Zero- defects was an impractical ideal.

However, some people who disagree with Juran's idea hold the opinion that the mistakes are caused by two factors: lack of knowledge and lack of attention. Knowledge can be measured and deficiencies corrected through tried and tested means. Lack of attention must be corrected by the person himself of herself through an acute reappraisal of his or her moral values. This is an attitude problem. The person who commits himself or herself to watch each detail and carefully avoid error takes the giant step toward setting a goal of zero-defects in all things, and the total quality will be achieved at the same time.

Another point is that because of the scientific and technological progress, many instruments can replace our hands to work. The chance of the substandard product presents is totally reduced. Taguchi, an economist of Japan proposed that if we increase more resources and pay more attention on preventing and assaying the products, and he implies that design of production line has a vital quality function, the zero-defects can be reached (Francois, 2003).

The new design of production line, though it makes the factories produce amount of production with high speed and the individual is only responsible for a small part of the production process. The quality control is mainly through the 
professional checks one by one. But with the vast number of the products and the increasing of diversification of the types, the professionals are unable to check the products one by one. They only rely on a few as the samples to check, therefore, there must be some substandard products flow into the market, and the total quality can not be achieved.

In fact, the zero-defects is not something that originates on the assembly line. To create a manufacturing process that has zero-defects management must set the tone and atmosphere for employees to follow. If management does not create a system by which zero-defects are clearly the objective then employees are not to blame when things go astray and defects occur. The benefit for companies of such a system is a dramatic decrease in wasted resources and time spent producing goods that consumers do not want and the total quality control will be failed and the total quality will be never achieved.

\section{The total quality management}

Total quality management is an overall business quality improvement system. It is as brand or system to guarantee the aspiration of total quality. It encourages participation amongst shop floor workers and managers. There is no single theoretical formalization of total quality, but Deming, Juran and Ishikawa provide the core assumptions, as a "...discipline and philosophy of management which institutionalises planned and continuous... improvement ... and assumes that quality is the outcome of all activities that take place within an organization; that all functions and all employees have to participate in the improvement process; that organizations need both quality systems and a quality culture." (John Peter, 1994) Generally speaking, the success of total quality not only is reliant on an understanding of the strategic objectives of organizations but also is dependent on the interworkings of these areas.

Deming believed that poor worker attitudes are symptoms of supervisor inability to lead. He stressed again and again that it is the system, which produces errors, not people. As such, it isn't the work force that needs attention; it's the controllers of the system, management. That means the organizations need the total quality management to realize their objective of total quality. However, how to do the total quality management is a big problem to many firms. Many managers thought they can use the theories of total quality management such as the quality circles, the quality control, giving some training to the employees and asking them to fully participate to achieve the total quality. Through the efforts of more than ten years, except the example of Xerox reached obvious success, the achievement of others are not remarkable (Francois, 2003). The reason just as Peter S. Pande puts some notes in his book "The Six Sigma Way" is that the concepts of total quality management lacks experienced administration and supervision authorities to pursue from top to bottom. Most of the managers can not get clear idea of their goals to pursue, and they do not know how to achieve the goals. So most of the time, the organisations are waste the resources and time. Due to this situation, the leadership for the total quality management has problems in many companies. Though the total quality is a difficult, comprehensive, and long-term process, leaders will need to maintain their commitment, keep the process visible, provide necessary support, and hold people accountable for results. Use input from stakeholder (clients, referring agencies, funding sources, etc.) as possible; and, of course, maximize employee involvement in design of the system. The top management and the middle management should focus on the vital few goals, aligning of activities, maintaining constancy of purpose, and creating an environment where employees are not fearful of exposing weaknesses. This may the only way for leading the commitment and the organization's total effort to ensure that the total quality be achieved.

Second, the cost of quality should be measured in terms both of conformance and of non-conformance when doing the total quality management.

To use Six-Sigma is one of the success ways, for it defines a clear road map to achieve total quality. Motorola is known worldwide as a quality leader. To accomplish its quality and total customer satisfaction goals, Motorola concentrates on several key operational initiatives. At the top of the list is "Six Sigma Quality," a statistical measure of variation from a desired result. In concrete terms, Six Sigma translates into a target of no more than 3.4 defects per million products, customer services included. At the manufacturing end, this requires "robust designs" that accommodate reasonable variation in component parts while providing consistently uniform final products. Motorola employees record the defects found in every function of the business, and statistical technologies are made a part of each and every employee's job. To achieve the company's objectives, Motorola spent in excess of \$170 million on worker education between 1983 and 1987 (Tomas Pyzdek, 1999).

However, how many companies can have as much financial support as Motorola? To pursue the quality is a kind of investment and needs amount of fees. "Quality is free", but "the total costs of prevention are less than the costs of failure." (Naylor, 1999) In fact, the quality programmes would eventually pay for themselves. Organisations are managed and face the challenge of the violent competitions of the liberalization, globalization in 21 st century. The customer apt to change and the brand operator must cost more on their quality investment. They spend such limited budget and only to pursue the uncertain results and want to achieve the endless goals. We can not imagine what will happen in the firm once it has cut its costs of failure. It will become more difficult to achieve and may be difficult to justify in financial terms (Naylor, 1999). Unless the substantial benefits can be achieved very quickly, the firm with a shortage of financial resources may prefer to invest in other areas of business development, though they know how the 
importance of improving the quality of their products.

Furthermore, the quality management becomes a kind of professional technique, and needs specialized professionals to do it. The organisations should invest a large amount of training funds to do the relevant technical training to the staff and to achieve their planning. This is very hard for the small organisations for they could not bear so much money on training and the total quality of theirs may never be reached.

Third, the long-term continuous improvement is the ultimate aim of a quality initiative. Total quality management is mainly concerned with continuous improvement in all work, from high level strategic planning and decision-making, to detailed execution of work elements on the shop floor. It has a strong belief that mistakes can be avoided and defects can be prevented. It leads to continuously improving results, in all aspects of work, as a result of continuously improving capabilities, people, processes, technology and machine capabilities (Rodney Macdam, 1998).

Continuous improvement must deal not only with improving results, but more importantly with improving capabilities to produce better results in the future. "As its core, total quality management is a simple idea. The research for competitive advantage through quality is best sustained by applying basic ideas right across the organisation. Yet, in spite of strong arguments for quality programmes, many companies have not carried out change successfully." (Naylor, 1999)

The continuous improvement is an on-going process, and it is changing. During the process of change, it may be desirous to remove non-value-added activities, shorten cycle times and improve other organizational performance measures. However, this often results in large-scale disruption to the change project and often its ultimate failure. That is because most of the employees who, "because of pre-existing problems, find it impossible to join in will not support the change. The TQM development may, therefore, make current social tensions worse." (Naylor, 1999) Thus, while total quality philosophy is built on improving business performance measures and changing roles and systems to suit, it has not integrated the personal ambitions and desires of the individual who perform these roles and are affected by these systems.

Changing culture, attitudes and behaviours is another related issue. It is assumed that mechanistic changes brought about by a change project will ultimately result in the fundamental change in these factors. However, as Peter and Waterman point out, employees only respond quickly to change when the new culture proclaimed is one to which they can relate to, share and ultimately shape. The total quality assumptions concerning cultural change are at best shallow and ignore the enormous complexity of organization culture and its historical roots. These themes are echoed by Towers (1993), who points out that "cultural change is not easy, not only does it involve structural re-arrangements but demands personal commitment".

Kottler(1995) states that a key reason for failure in change initiatives is "not anchoring changes in the corporation's culture", he states that change only sticks when it becomes "the way we do things around here ... when it seeps into the bloodstream of the corporate body". Thus, unless desired behaviours are rooted in social norms and shared values, they are subject to degradation as soon as the pressure for change is removed. A purely mechanistic approach cannot adequately address this issue. Collins (1994) talks of the lack of balance between control and quality of working life in total quality and points out that total quality management has made simplistic assumptions regarding the cultural side of total quality, so it is hard to realize the total quality.

\section{Conclusion}

Total quality is very important to the organisation. It is the insurance of the quality of their products that is for the quality is the life of every organisation. Though every organisation is eager to reach the total quality, it is very difficult and sometimes it seams impossible. To achieve the total quality, should be supported by the total quality control system and the total quality management. If neither of them can be worked well or has some problem, the achievement of total quality will not be realized. According to the above discussion, in the aspect of total quality control, no matter how advanced the system or the production line is, it still exists the inevitable personal mistake. This makes the total quality is hard to achieve. In the field of total quality management, the investment of training, the changing culture, the costs of quality, the long-term continuous improvement and so on are the limitation of the total quality management. People can not solve these kinds of problems and these are the reasons about why the achievement of total quality is regarded as an impossibility.

\section{References}

Adian. Wilkin. (1998). Managing with total quality management: theory and practice. Basingstoke: Macmillan Business.

Collins. P. (1994). Approaches to quality. TQM Magazine, Vol. 6 No. 3. pp. 39-43.

Dale. E. Zand. (1993). Managers and Consulting: A Total Quality Perspective. The Journal of Management Development. Vol. 12 No. 7. 
Everett, C. (2002). Penn states commitment to quality improvement. Quality Progress, Vol. 35 No. 1, pp. 44-9.

Francois, P., Peyrin, J.C., et al. (2003). Evaluating implementation of quality management systems in a teaching hospital's clinical departments, International Journal of Quality Health Care, Vol. 15 No. 1, pp. 47-55.

Fred Palumbo et al. (1994). Total quality and the human resource professional. Training for quality, Vol.2 No.1, pp 29-34.

Kottler. J. (1995). Leading change: why transformation efforts fail. HBR, March- April. pp 59-67.

Naylor. J. (1999). Management. London: Financial Times Prentice Hall.

Peters. J. (1994). Operationalizing total quality: a business process approach. The TQM Magazine. Vol. 6 No.4, pp 29-33

Rodney. M et al. (1998). The links between organisational learning and total quality: a critical review. Journal of European Industrial Training. Vol. 22 No. 2, pp 47-56.

Sinclair, D. and Zairi, M. (2001). An empirical study of key elements of total quality-based performance measurement systems: a case study approach in service industry, Total Quality Management, Vol. 12 No. 4, pp. 535-50.

Towers. S. (1993). Process re-engineering—lessons for success, Management Services, August. 